\title{
A VIOLÊNCIA ANIMADA: NOTAS SOBRE ASSOCIAÇÕES ENTRE A VIOLÊNCIA, O HEROÍSMO E SUA INFLUÊNCIA SOBRE A CRIANÇA
}

\author{
Raveni Joazeiro Silva* \\ Ana Lucia Castilhano**
}

\begin{abstract}
RESUMO: As séries de animação ou desenhos animados que trazem como protagonistas super-heróis são bastante populares e têm em comum a presença de cenas de violência física nos momentos de resolução de conflitos e enquanto ápice da luta pela defesa moral pelo bem-estar da humanidade. Os super-heróis retratados nos desenhos usam uniforme, têm poderes sobre-humanos ou acesso a recursos tecnológicos avançados para combater o crime. Dedicam-se à missão de proteger a humanidade de qualquer ameaça, tendo como mais alto valor a justiça, ainda que isso implique matar pessoas e criaturas, destruir prédios e cometer atos de violência. Podese constatar que a associação entre heroísmo e violência física e, até mesmo entre justiça e violência, são aspectos apresentados nos desenhos animados. Este trabalho procura demonstrar, através de revisão bibliográfica, como os atos de violência física estão associados a atos considerados heroicos dentro do universo da trama do desenho animado, apresentando-se como moralmente justificado ou necessário e como isso tem influência na resolução de conflitos reais por parte da criança, além de sua influência no brincar.
\end{abstract}

Palavras-chave: Desenho animado; violência; super-herói.

\section{ANIMATED VIOLENCE: NOTES ON ASSOCIATIONS BETWEEN VIOLENCE AND, HEROISM AND THEIR INFLUENCE ON CHILDREN}

\begin{abstract}
Animated series or cartoons that feature superheroes as protagonists are quite popular and have in common the presence of scenes of physical violence in moments of conflict resolution and as the culmination of the struggle for moral defense for the welfare of humanity. The superheroes portrayed in these animations wear uniforms, have superhuman powers or access to advanced technological resources to fight crime. They are dedicated to the mission of protecting humanity from any threat, with justice as the highest value, even if it means killing people and creatures, destroying buildings and committing acts of violence. We found that the association between heroism and physical violence, and even between justice and violence, are aspects presented in these cartoons. Thus, this work seeks to demonstrate, through a bibliographic review, how the acts of physical violence are associated with acts considered heroic within the universe of the plot of the cartoon, presenting themselves as morally justified or necessary and how this has an influence in the resolution of real conflicts by the child, in addition to its influence on playing.
\end{abstract}

Keywords: Cartoon; violence; Super hero.

\footnotetext{
* Bacharel e licenciada em Psicologia pela Universidade Estadual do Sudoeste da Bahia, pós-graduanda em Psicopatologia Psicanalítica pela Unigrad, polo Vitória da Conquista, Bahia. rhavenny@hotmail.com. ORCID: 0000-002-3933-3094.

** Professora do Curso de Psicologia da Universidade Estadual do Sudoeste da Bahia, Doutora em Educação pela UFSCar. alcastilhano@gmail.com. ORCID: 0000-0003-3554-828X.
} 
Os super-heróis das séries animadas são personagens com os quais as crianças convivem de forma estreita há pelo menos seis décadas. É possível notar a maneira como o imaginário infantil se constitui em torno dessas figuras, como o comportamento da criança é afetado e como determinados personagens servem de modelos que são imitados e podem fazer parte de uma composição sobre como a sociedade funciona para a criança.

Os super-heróis das séries animadas segundo Luyten (2000), circulam num espaço mítico e nem sempre têm uma relação direta com a realidade ou a atualidade, mas representam a cristalização de necessidades e tendências, como fantasmas de uma determinada época. Talvez possamos compreender o desenho animado como produção que realiza uma mediação entre uma geração de adultos, ou várias, e as crianças. As animações possuem linguagem própria baseada em imagens que se sucedem, em grande parte, de forma dinâmica, conseguindo ter acesso, inclusive, à atenção de criança bem pequenas. Talvez as lutas entre personagens façam parte desse dinamismo próprio desse tipo de mídia. O fato é que grande parte das animações apresentam situações de violência física entre seus personagens.

A violência física aparece, nas animações, como um mecanismo na resolução de conflitos entre os super-heróis e os vilões, que podem ser representados como monstros, alienígenas ou seres humanos, estes, apresentando transtornos mentais ou não. A Organização Mundial de Saúde (KRUG, 2002, p. 5) define violência como: "o uso intencional da força física ou do poder, real ou em ameaça, contra si próprio, contra outra pessoa, ou contra um grupo ou uma comunidade, que resulte ou tenha grande possibilidade de resultar em lesão, morte, dano psicológico, deficiência de desenvolvimento ou privação".

Não se pode ignorar como os protagonistas dos desenhos animados com linguagem violenta se portam e o modo como parecem afetar os comportamentos dos espectadores (KASPRZAK, 2003), principalmente aqueles para os quais geralmente esses programas se direcionam: o público infantil. Em geral, essas animações apresentam uma ideia do que é heroísmo e, por conseguinte, podem apresentar uma associação entre a justiça, encarnada no super-herói, e a violência utilizada por ele para combater o crime ou a desordem. Esse tipo de situação se apresenta mais dramática nas crianças de três ou quatro anos, pelo seu comportamento amparado na imitação e na resolução de problemas por meio do uso do corpo.

Uma questão importante para essa discussão é estabelecer a diferença entre violência e agressividade. Para Ferrari (2006) a violência é sintoma que supõe “[...] uma ordem instituída da qual emerge, manifestando aquilo que não funciona bem em tal ordem estabelecida, aquilo que impede a intenção de felicidade, ou melhor, que impede o princípio do prazer" enquanto a agressividade seria parte do instinto.

Para Freud (1974), a agressividade humana não é aquela que se observa nos animais, expressa na luta pela conservação da espécie. Embora se aproxime da noção de instinto animal, hereditariamente 
fixado, apresenta-se como uma potência sem objeto específico. A agressividade humana, para Freud, demonstra outra herança: a inscrita na ordem social, referente à permanência de uma lei à qual o humano se submete e faz com que ele se articule sob aspectos de proibição, hostilidade e ética, como descrito no mito apresentado em sua obra Totem e Tabu, na qual o ser humano abandonaria o incesto e a violência predominantes em seu estado arcaico para estabelecer um contrato social no qual atos dessa natureza estariam proibidos. (KOLTAI, 2010).

A agressividade age também como parte da autopreservação em situações de perigo ao indivíduo ou ao grupo, tanto entre seres humanos quanto entre animais. Assim, considerando a diferença entre necessidade e desejo encontramos uma distinção fundamental entre o instinto agressivo do animal e a violência humana, a qual consiste no fato de o campo animal ser composto por necessidade e não por desejos. Nas Reflexões para os tempos de guerra e morte (FREUD, 1974) a violência é um instrumento de que o homem dispõe para organizar as leis e o direito, ou seja, não há um determinante biológico para que a agressividade se torne violência, mas sim um desejo. Encontraremos, no Mal-estar da civilização (2011) e em Além do princípio do prazer (1976), a violência enquanto uma manifestação da agressividade, que por sua vez é parte do instinto humano, mas que, se voltado para a diplomacia, permite a resolução dos conflitos por meio do diálogo e da cooperação.

Podemos definir a agressividade como uma característica instintiva presente em todos os animais, inclusive no ser humano, e a violência como um comportamento que agrega tanto o fruto de um desejo impedido como uma exteriorização deste instinto quando, de alguma forma, o diálogo ou a evitação do conflito não têm vazão ou são barrados. Sob uma outra perspectiva, a violência também pode ser compreendida como imitação de um comportamento apreendido em situações sociais ou através das mídias.

\section{Do heroísmo}

A palavra herói provém do grego n்œwas/heros/, e significa protetor ou defensor (KINSELLA; RITCHIE; IGOU, 2017). Nas histórias contadas por meio de mitos nos formatos de peças, epopeias, poemas, e outras produções, o herói é aquele que deveria passar por uma jornada e, ao longo dessa jornada, colher algum tipo de conquista ou transformação.

O tema do herói é apresentado por Joseph Campbell (1995), em seu livro o Herói de Mil Faces, e por Christopher Vogler (2009), em A Jornada do Herói. Segundo o primeiro, essa narrativa aparece muito associada ao modo como diversos povos apresentam seus heróis em contos de fadas, mitos e lendas no que ele chamou de monomito, pela semelhança entre a trajetória dos heróis de diversas culturas em diferentes épocas. Para Campbell (2007,p.36) “ [...] o percurso padrão da aventura mitológica do herói é uma magnificação da fórmula representada nos rituais de passagem: separação-iniciação-retorno que podem ser considerados a unidade nuclear do monomito."

A saída de um estado de dependência paterno ou materno por um chamado divino, superior, um 
desejo ou necessidade eminente de deixar esse lugar é seguida do encontro com um guia, um guru, mentor juntamente com o enfrentamento de inimigos e medos. Esse processo de iniciação envolve a aventura, o encontro com amigos, inimigos, guias e aparatos sobrenaturais que auxiliam o herói, como amuletos e armas, testes de confiança, força e coragem, sacrifícios, treinamentos e também algum tipo de resolução ou superação de algum aspecto negativo do passado do herói assim como situações de conciliação com a morte (CAMPBELL, 1995; VOGLER, 2009).

Quando a missão é cumprida, há o retorno ao local de origem no final da viagem. Para essa nova pessoa que retorna da jornada, o ambiente do qual saiu pode ser visto como um lugar de calmaria e conforto, ou como um local ao qual não se pertence mais. Podemos observar os dois modelos de retorno do herói em duas obras diferentes de autoria de J. R. R. Tolkien. Em O Hobbit, (TOLKIEN, 2009), o retorno do personagem Bilbo ao Condado se dá como algo desejado, um retorno à calmaria de seu lar. Já em O Senhor dos Anéis (TOLKIEN, 2002), outro personagem, Frodo enfrenta desconforto e desadaptação ao retornar ao lar após enfrentar sua jornada. É interessante perceber a relação de fatores como a mudança pela qual o herói passa e o significado que suas experiências têm para ele quando retorna para sua vida anterior.

Conforme dito anteriormente, essa jornada é repetida diversas vezes nas histórias de heróis apresentadas através de relatos orais, livros, filmes, histórias em quadrinhos, animações, role playing games de mesa e virtuais, entre outros anacrônicos aos valores contemporâneos ou não.

Vogler (2009) relaciona o herói com a função do ego em termos de sua separação da família ou da tribo como uma separação da mãe pela qual as crianças passam. O autor comenta a função psicológica do herói:

O arquétipo do Herói representa a busca de identidade e totalidade do ego. No processo de nos tornarmos seres humanos completos e integrados, somos todos Heróis, enfrentando guardiões e monstros internos, contando com a ajuda de aliados. Na busca de explorarmos nossa própria mente, encontramos professores, guias, demônios, deuses, companheiros, servidores, bodes expiatórios, mestres, sedutores, traidores e auxiliares, como aspectos de nossas personalidades ou como personagens de nossos sonhos. Todos os vilões, pícaros, amantes, amigos e inimigos do Herói podem ser encontrados dentro de nós mesmos. A tarefa psicológica que todos enfrentamos é integrar essas partes separadas em uma entidade completa e equilibrada. $\mathrm{O}$ ego - isto é, o Herói que acha que é separado de todas essas partes de si mesmo — deve incorporálas para se tornar um ser integral. (VOGLER, 2009, p. 52.).

Vogler (2009, p. 201) também aponta para o clímax da narrativa que "deve provocar a sensação de catarse". Esse expurgo ou libertação emocional faz uma analogia com uma expansão emocional descrita por Aristóteles (2015) sobre as tragédias heroicas gregas: o efeito no espectador que ia ao teatro para que esse expurgo ocorresse na identificação com as situações trazidas nas peças. Aqui temos a atuação de um processo de identificação do leitor ou público com a situação vivenciada pelo herói, do clímax à resolução das narrativas. 
Ainda em relação à questão do herói, Kinsella, Ritchie e Igou pontuam, a partir de vários autores alguns complementos ao conceito de herói, questões como ideais de auto-imagem, reflexos dos valores sociais, ações relacionadas à promoção de padrões de conduta, méritos, realizações incomuns e atos altruístas e corajosos. Os heróis também apresentam preocupação com a proteção e promoção do bemestar das futuras gerações e capacidade para reagir diante das situações de maneira correta. (KINSELLA; RITCHIE; IGOU, 2017, p.20).

Em relação ao próprio ato heroico, Zimbardo, Franco e Blau (2011, p. 1) definem heró́smo como aquilo que "[...] representa o ideal dos cidadãos transformado em virtudes cívicas na forma maior de ato cívico, aceitando perigos físicos ou sacrifício social" (tradução nossa). O heroísmo se constituiria na ação do herói. Os autores ainda apontam para alguns aspectos do heró́smo como aquele trazido pela literatura, onde o herói se associaria a vários tipos de ações corajosas; a presença de risco, na trajetória do herói, acompanhando seu comportamento pró-social; e a diferença entre este comportamento e fatores sociais como o altruísmo e a compaixão. Um ponto importante na reflexão dos autores é o alerta para, ao nos concentrarmos no lado positivo dos ato pró-social, esquecermos de características às vezes negativas do fenômeno.

Ainda sobre o chamado comportamento ou ato pró-social Tulloch (1995, p. 98) o define como "[...] aquele cujos caminhos e propósitos são socialmente aprovados e aceitos dentro dos padrões morais de um grupo."

Zimbardo apresenta três tipos de heroísmo: o civil, o militar e o social. Todos, porém trazem características em comum como envolver um nível de perigo ou sacrifício para além do esperado em outros comportamentos pró-sociais; apresentar disposição para entrar em uma situação preocupante, apesar das claras barreiras à sua resolução e caminhos óbvios de saída; e transcender um medo considerável de agir (Zimbardo \& Franco, 2006; Zimbardo, 2007). Glazer \& Glazer (1999) agregam o aspecto de recusar ou não obter qualquer ganho secundário ou antecipado por conta de suas ações como uma característica heroica, o herói não deve discriminar a quem defende e não busca recompensas. Estes últimos seriam aspectos recorrentes nos heróis de séries animadas.

\section{Do Herói ao Super-Herói}

Para Campbell (1949, apud KINSELLA; RITCHIE; IGOU, 2017, p. 1) os heróis atuam como “[...] suporte para toda a vida humana e uma inspiração para a filosofia, poesia e as artes", agindo como "um veículo para a mais profunda instrução moral e metafísica.".

Os heróis também podem estar associados a uma representação cultural e atuam como fonte de controle social, influenciando indivíduos e grupos e sugerindo a atuação de heróis em movimentos, instituições, regimes políticos, períodos históricos e vida cotidiana (KLAPP, 1954) e pode condicionar ao que Becker (1973) chama de uma imortalidade simbólica do herói. 
Capparelli, Meurer e Kasprzak (2003) apontam que as narrativas sempre tiveram uma função fundamental na história da humanidade, pois dialogam com os problemas humanos e as verdades da existência. O desenho animado pode representar um recurso de interpretação da realidade posta sendo o heroísmo nele retratado como um anseio ou desejo humano de reagir a situações injustas ou também perigosas.

Luyten (2000), ainda afirma que a cultura fornece ao sujeito os sistemas simbólicos de representação da realidade, ou seja, o universo de significações que permite construir a interpretação do mundo real. Segundo McLuhan (1964), os meios de comunicação são extensões do homem no sentido de que consistem em metáforas ativas que traduzem a experiência da relação do homem com o mundo.

Ao longo do tempo, o formato das narrativas de heróis se diversificou, as lendas deixaram a narrativa oral e passaram a ocupar os folhetins e sessões em jornais e em 1938 passa a ser comercializada como história em quadrinhos, os Action Comics, para então se tornarem desenhos animados. A primeira história em quadrinhos de super-heróis, do Superman, também foi precursora do primeiro desenho animado que trazia como protagonista um super-herói.

Criados do final da década de 1930 a 1940, os super-heróis formam uma categoria de heróis com poderes ou habilidades sobre humanas, sejam eles originários de outros planetas, como o Superman, sejam dotados de inteligência e tecnologia, como o Homem de Ferro, sejam modificados em laboratório como o Hulk. Publicados pela Editora DC Comics e Marvel Comics, os super-heróis passaram ao cinema com grande sucesso do público infantil e adulto.

Segundo Barbosa Júnior (2002, p. 17), através da arte pode-se “[...] recriar o mundo como forma de compensação aos rigores da experiência no ambiente real [...], que permite elaboração de símbolos". Logo o símbolo é o super-herói e o desenho animado, um veículo de representação do mundo.

\section{Violência e Comportamento}

Quando partimos da ideia de que o super-herói age de maneira moral, não podemos nos esquecer de que "[...] toda moral consiste num sistema de regras e a essência de toda moralidade deve ser procurada no respeito que o indivíduo adquire por estas regras" (Piaget, 1994, p. 23). Logo a regra traz em si a instância do que é moral. Ser moral, neste sentido, é agir de acordo com as regras e prezar para que sejam respeitadas e acolhidas pelos membros de uma comunidade.

Para Piaget (1994), existem duas análises para a moralidade: o pensamento verbal teórico e o pensamento moral efetivo. Sobre o primeiro, o autor coloca-o no âmbito das situações hipotéticas de conflito moral, como as situações que aparecem nos desenhos animados. Este tipo de juízo está atrasado, 
ou seja, é anterior, em relação ao pensamento moral efetivo, o qual o sujeito realiza diante de situações reais de conflito. Ou seja, o pensamento verbal teórico seria como um treinamento para o conflito real.

A maneira como um super-herói resolve um conflito pode influenciar no brincar da criança, que imita o personagem (KASPRZAK, 1997), como um treinamento para uma ocasião real. Isso pode justificar o comportamento das crianças no clássico experimento do João-Bobo de Albert Bandura no qual, após assistir a cenas de ataques violentos aos bonecos por parte de um adulto, registrava-se que a criança imitava o comportamento assistido no boneco. Os experimentos de Bandura apresentam a chamada aprendizagem por observação. A experiência dá sentido ao imaginado, o que não impede a criança de perceber "[...] também que as regras não são cristalizadas, nem muito menos são de origem divina ou de um adulto" (SOUZA; VASCONCELOS, 2009, p. 344).

O filósofo Kant (1960) acreditava que os preceitos morais estão atrelados à noção de justiça, deveres e obrigações morais sendo a razão o principal aspecto da moralidade, logo o respeito à regra é uma necessidade racional e lógica. Assim, o ser humano seria inevitavelmente moral, se fosse racional. Quanto à moral, Kohlberg (1992) avalia que existem dois tipos de juízo moral: o primeiro, de estrutura, referente a uma argumentação ou justificativa da escolha feita, uma racionalização da necessidade, como descrito por Kant. O segundo seria um juízo moral de conteúdo, revelado a partir da escolha da resposta ao dilema, no caso dos desenhos, ao conflito.

Assim, o desenvolvimento moral para Kohlberg (1992) dá-se em estágios estruturados das noções de justiça, que são construídos em função das interações sociais, além de organizarem e serem organizados pela sociedade em que o sujeito vive. É na interação entre as condições internas (maturidade do sistema nervoso, níveis do desenvolvimento cognitivo) e externas (possibilidade de assumir papéis ou mudar de perspectiva) que o sujeito avança em cada estágio e torna-se capaz de construir modos de pensar e raciocínios morais mais avançados que os anteriores. Kohlberg não exclui o desenvolvimento paralelo das estruturas cognitivas e as do desenvolvimento moral. Ele afirma que existe uma relação entre ambas, concordando com as proposições de Piaget, e transpondo a ideia piagetiana de hard stage sobre o desenvolvimento cognitivo para o desenvolvimento do juízo moral. A capacidade de formar juízos mais evolúídos necessita não só do conhecimento das regras e normas, mas também do desenvolvimento de estruturas cognitivas, o que possibilita a descentralização e a coordenação de perspectivas, necessárias ao avanço no juízo moral, pois permite a comparação, o estabelecimento de relações, a hierarquização e a classificação dos elementos envolvidos. No entanto, o desenvolvimento cognitivo é necessário, porém não suficiente para o desenvolvimento moral. (SOUZA; VASCONCELOS, 2009, p. 346).

O super-homem da ficção da Editora DC Comics é mais que um homem ou é um deus reunindo em si poderes sobre-humanos: emite raio laser dos olhos, é mais forte do que qualquer animal na face da terra, voa e, apesar de parecer terráqueo, é um alienígena enviado pelos pais numa fuga de um planeta em destruição. É moralmente mais evoluído e quase nunca é contestado, mesmo quando faz uso da violência 
física para proteger seu novo lar e seus amigos. É uma história semelhante a de diversos outros superheróis da atualidade e da antiguidade.

Kasprzak (1997) afirma, em sua dissertação de Mestrado, que os desenhos influenciam no brincar das crianças pré-escolares: elas se imaginam como personagens do desenho, com as mesmas características de personalidade ou poderes, pois estes são aspectos desejáveis de pessoas boas e morais. Podemos observar também, na brincadeira infantil, movimentos e exercícios que lembram a mobilidade e os atributos físicos dos heróis.

Não há como negar, portanto, que as produções audiovisuais influenciam no comportamento e no julgamento moral de quem as consome. Sirqueira (2008) menciona a existência de um controle simbólico por esta mídia: as cenas apresentadas nos desenhos animados são dadas ao espectador como uma possibilidade e exemplo do que ocorre ou pode ocorrer no mundo real. Neste caso, o pensamento verbal teórico de Piaget e o julgamento e baseado na moral de estrutura de Kohlberg (1992), seria desenvolvida no herói adulto, mas não no brincante infantil.

Além disso, o desejo de justiça é trazido por Mahfoud (2012) como uma exigência constitutiva da pessoa, uma necessidade ou anseio humano que pode ser satisfeito pelo super-herói detentor da moral mais elevada, porém prevalece enquanto desejo para se tornar necessidade quando a situação oportuna para o clamor por justiça aparecer. Este anseio por justiça está pautado pelo respeito da moral e o superherói é necessário, pois a sociedade não dá conta de se proteger ou contra-atacar suas ameaças sozinha. Benelli (2002, p. 21) afirma que a agressividade não canalizada para fins socialmente úteis converte- se em violência". O autor pontua a violência como "[...] uma variante de um tipo de relação com a lei, uma modalidade de subjetividade específica", em um processo ou “[...] estratégia de sobrevivência em ambientes hostis".

Tanto a violência como o conceito de fazer justiça com as próprias mãos são características culturais que podem ser facilmente observadas nos desenhos animados. Embora as leis e discursos formais expressem o contrário disso, aparentemente, lidamos com um processo de massificação de certos comportamentos presentes em grande medida nas animações consumidas pelas crianças. Esse aspecto pode ser pensado a partir de um ponto de vista cultural e talvez pedagógico que autoriza o uso da violência em uma sociedade que prega a não-violência, como Bandura chamou atenção em sua obra na década de 1970. Seria possível ocorrer imitação e recriação dessas características violentas nos jogos infantis tendo como base as mesmas narrativas.

Soares (2017) apresenta, em sua monografia, a fala de duas crianças sobre sua experiência com programas infantis. Uma delas, de cinco anos, cujo desenho animado favorito é As Tartarugas Ninja, afirma que o que aprendeu "de legal" foi ver os personagens lutando, e o motivo de gostar é que "elas 
vencem sempre". Outro menino de cinco anos, cujo desenho favorito é Power Rangers, responde que o que mais gosta no programa, é que eles lutam e combatem o mal. A criança diz que o que melhor aprendeu é que o bem sempre vence no final. Apesar de Power Rangers não se enquadrar na categoria de desenho animado, ele possui diversos elementos em comum, dos quais destacaríamos dois deles: o fato de serem voltados para crianças e de terem como tema a luta física e o confronto com um adversário. As crianças precisam lidar com um mundo muito maior do que elas, do qual pouco sabem e que está muito além do seu controle. Neste sentido, tanto a ideia de catarse, abordada anteriormente, como os esforços infantis para elaborar conceitos de moral e justiça, como também a possibilidade de encarar uma luta e sair bem-sucedido dela são fatores que não podem ser ignorados, especialmente pelas famílias e pelas escolas.

\section{Considerações Finais}

Apresentamos, no presente artigo, um conjunto de abordagens sobre alguns aspectos importantes para se compreender o papel das séries animadas como produção cultural e como representação de um determinado contexto social perante as crianças. Não é possível pensar num produto de mídia como os desenhos animados sem ter em mente a influência geracional que ele tem ao longo do tempo. Não se pode descartar a possibilidade de a violência física ser um dos atrativos desses produtos, mas não somente este aspecto deve ser considerado relevante. A figura e o ideal do herói conversam com as dificuldades e situações que marcam passagens simbólicas de crescimento e amadurecimento humano e mostram um campo psicológico receptivo a essas produções.

Sendo as séries animadas produto de nossa época e influentes nos comportamentos e atitudes de seus espectadores, também demonstram seu potencial didático, expressivo e simbólico e, portanto, não estão isentos às críticas a respeito da criação e propagação de estereótipos físicos e de comportamento, inclusive apoiados na construção psíquica através das brincadeiras infantis: no faz de conta, na reprodução e na subversão das situações diante do roteiro original e dos roteiros feitos durante o brincar. Estes são, inclusive, pontos que podem ser explorados em artigos e pesquisas em educação e psicologia. Pontos estes muito importantes, ao nosso ver, para permanecerem praticamente em um grupo muito particular de interesses acadêmicos.

Nesta tentativa de realizar uma conceituação ampla do que é violência, heroísmo e moral é possível notar ao longo do texto como definições e conceitos de diversos autores conversam entre si. Também é possível avaliar quais indagações podem ser apresentadas às crianças a respeito de seus comportamentos e da imagem que formam sobre o que é ser herói, com quais deles elas se identificam, e quais recortes de classe, gênero e diferenças sexuais apresentados nessas mídias contribuem para propagação de comportamentos violentos e discriminatórios para com seus pares, a partir da 
apresentação de estereótipos de vilões, vilãs, mocinhos, mocinhas e heróis e heroínas, promovendo práticas mais adequadas a seu consumo e sua socialização.

Tendo em vista a associação de um valor moral e de justiça, a um símbolo contemporâneo como o super-herói, é pertinente lembrar que existe uma evolução desta imagem mostrada nos desenhos juntamente com o amadurecimento cognitivo de quem os assiste, e que mudanças culturais também podem proibir ou permitir cenas antes admissíveis ou reprováveis, dando a este tipo de entretenimento novas roupagens mais condizentes com seu contexto histórico. Os desenhos também trazem arquétipos sobre quem se é, quais as tragédias na narrativa heroica (e na vida), quem é o inimigo, além de ideias a respeito de amizade e inimizade, amadurecimento e destino. É necessário também ressaltar que os desenhos animados não são as únicas produções consumidas e influenciadoras durante nossas vidas e não devem ser condenados como tais. Ainda há muito que se refletir e se pontuar a respeito pois o tema da violência nas animações é complexo e ainda demanda muito trabalho por parte dos estudiosos de diversas áreas de conhecimento, mas em especial, da educação, da psicologia e da sociologia.

Diante da importância dos programas infantis aos quais as crianças têm acesso muitas vezes irrestrito, acreditamos que ainda há pouco escrito sobre o assunto. Crianças de todas as idades, algumas bem pequenas, são deixadas à frente da televisão e atualmente, de outros tipos de tela de exibição e interação com tablets, celulares e notebooks, em plataformas como Youtube, streamings e redes sociais. O fato é que o acesso das crianças a conteúdos como séries animadas e outros tem sido cada vez mais facilitado. Um fenômeno como esse demanda não só uma discussão ampla no meio social e educacional como também uma ampliação nos estudos a respeito da influência que os comportamentos dos personagens têm sobre as crianças. Nesse caso, estudos como o de Bandura se tornam, apesar de tantas décadas terem se passado, relevantes como ponto de partida para se compreender fenômenos de aprendizagem e formação humana.

Há de se procurar saber mais sobre os efeitos que determinadas animações e heróis apresentam sobre as crianças ou como elas interpretam as ações dos personagens apresentados. Isso, não só sob um olhar crítico sobre o modo como a cultura vem apresentando suas contradições a crianças muito pequenas, mas também em termos dos modos como as famílias trabalham com essas questões e certamente, a maneira como as crianças interpretam aquilo que assistem. 


\section{REFERÊNCIAS}

ARISTOTELES, O. Ética a Nicomano. São Paulo: Martin Claret, 2015. 300 p.

BARBOSA JÚNIOR, Alberto Lucena. Arte da animação: técnica e estética através da história. 1. ed. São Paulo: SENAC, 2002. 456 p. ISBN 978-8573592191.

BENELLI, S. J. O internato escolar como instituição total: violência e subjetividade. Psicologia em Estudo, Maringá, ano 2002, v. 7, n. 2, p. 19-29, jul./dez. 2002.

BECKER, E. The denial of death. 1. ed. United States: Free Press, 1973. 336 p..

CAMPBELL, J. O herói de mil faces. 1. ed. São Paulo: Pensamento, 1989. 416 p.

CAPPARELLI, S.; MEURER, F. R.; KASPRZAK, R. G. As narrativas televisivas, sua dimensão mítica e sua importância na subjetivação infantil. Intercom, Rio de Janeiro, ano 1999, 31 out. 2020. Congresso Brasileiro de Ciências da Comunicação, p. 1-11. Disponível em: https://lume.ufrgs.br/handle/10183/427. Acesso em: 25 out. 2020.

FERRARI, I. F. Agressividade e violência. Psicologia Clínica, Rio de Janeiro, ano 2006, v. 18, n. 2, p. 4962, 2006.

FREUD, S. O mal-estar na civilização. 1. ed. São Paulo: Penguin Classics Companhia das Letras, 2011. 95 p.

FREUD, S. Reflexões para os tempos de guerra e morte. In: FREUD, S., Edição standard brasileira das obras psicológicas completas. Vol. XIV. Tradução J. Salomão. Rio de Janeiro: Imago, 1974.

FREUD, S. Totem e tabu. In: FREUD, S., Edição standard brasileira das obras psicológicas completas. Vol. XIII. Tradução J. Salomão. Rio de Janeiro: Imago, 1974.

FREUD, S. Além do princípio de prazer. In: FREUD, S., Edição standard brasileira das obras psicológicas completas. Vol. XVIII. Tradução J. Salomão. Rio de Janeiro: Imago, 1976.

GLAZER, M. P.; GLAZER, P. M. On the trail of courageous behavior. Sociological Inquiry, [S. l.], ano 69, v. 2, p. $276-295,1999$.

HORA de Aventura. Direção: Larry Leichliter. Produção: Kelly Crews; Pendleton Ward. Estados Unidos: Cartoon Network, 2008. 9 dvds.

KANT, I. Fundamentação da metafísica dos costumes. Coimbra: Atlântida, 1960. 120 p.

KASPRZAK, R. G. Desenhos animados em tempo de violência: uma contribuição para pensar a construção de valores sócio-morais em crianças pré-escolares. Orientador: Clary Milnitsky-Sapiro. 1997. 136 f. 
Dissertação (Mestrado em Psicologia do desenvolvimento) - Universidade Federal do Rio Grande do Sul, Porto Alegre, 1997.

KINSELLA, E. L.; RITCHIE, T. D.; IGOU, E. R. Attributes and applications of heroes: a brief history of lay and academic perspectives. In: ALISSON, S. T.; GOETHALS, G. R.; KRAMES, R. M. Handobook of heroism and heroic leadership. New York: Toutledge, 2017. p. 19-35.

KLAPP, O. e. Heroes, villains and fools, as agents of social control. American Sociological Review, Estados Unidos, v. 19, n. 1, p. 56-62, 1954.

KOHLOBERG, L. Psicologia del desarrollo moral. Bilbao: Desclée de Brower, 1992. 664 p.

KOLTAI, Catarina. Totem e tabu: um mito freudiano. Rio de Janeiro: Civilização Brasileira , 2010.

KRUG, E. G.; DAHLBERG, L. L.; MERCY, J. A.; ZWI, A. B.; LOZANO, R. World report on violence and bealth. Geneva: World Health Organization, 2002. 360 p.

LUYTEN, S. B. Mangá: o poder dos quadrinhos japoneses. 1. ed. São Paulo: Hedra, 2000. 250 p.

MAHFOUD, M. Experiência elementar em psicologia: aprendendo a reconhecer. Brasilia, DF: Universa; Belo Horizonte: ArteSã, 2012. 247p.

MCLUHAN, M. Os meios de comunicação como extensão do homem. São Paulo: Cultrix, 1964. 405 p.

PIAGET, J. O juíro moral na criança. São Paulo: Grupo Editorial Summus, 1994. 302 p.

SOARES, Iasmin Bezerra. Educação, infância e desenhos animados. Orientador: Alessandra Cardozo de Freitas. 2017. 54 f. Monografia (Bacharelado em Pedagogia) - Universidade Federal do Rio Grande do Norte, Natal, 2017.

SOUZA, Leonardo Lemos de; VASCONCELOS, Mario Sergio. Juízo e ação moral: desafios teóricos em psicologia. Psicologia Social. 2009, vol.21, n.3, pp.343-352. ISSN $1807-$ 0310. https://doi.org/10.1590/S0102-71822009000300007.

TOLKIEN, J. R. R. O Senhor dos anéis: o retorno do rei. Tradução Lenita Maria Rímoli Esteves e Amilo Pisseta. $3^{a}$ edição. São Paulo: Editora WMF Martins Fontes, 2002.

TOLKIEN, J. R. R. O bobbit. Tradução Lenita Maria Rímoli Esteves e Amilo Pisseta. $4^{a}$ edição. São Paulo: Editora Martins Fontes, 2009.

TULLOCH, M. I. Evaluating aggression: school students' responses to television portrayals of institutionalized violence. Journal of Youth and Adolescence, Journal of Youth and Adolescence, v. 24, p. 95115, 1995.

VOGLER, C. A jornada do escritor. estruturas míticas para escritores. Tradução de Ana Maria Machado. 2.ed. Rio de Janeiro: Nova Fronteira, 2006. 
ZIMBARDO, P. G. The heroic imagination: a talk with Phil Zimbardo. 2007. Disponível em:

https://www.edge.org/3rd_culture/zimbardo07/zimbardo07_index.html. Acesso em 25 de outubro de 2020.

ZIMBARDO, P. G. The banality of heroism. Great Good, Berkeley, p. 1-14, 1 set. 2006. Disponível em: https://greatergood.berkeley.edu/article/item/the_banality_of_heroism. Acesso em: 25 out. 2020.

ZIMBARDO, P. G.; FRANCO, Z. E.; BLAU, K. Heroism: a conceptual analysis and differentiation between heroic action and altruism. Review of General Psychology, [S. l.], v. 15, n. 2, p. 99-113, 1 jan. 2011. 